HISPANIA. Revista Española de Historia, 2006, vol. LXVI, núm. 222, enero-abril, págs. 109-130, ISSN: 0018-2141

\title{
LA HISTORIA MALEABLE. A PROPÓSITO DE INTERNET ${ }^{1}$
}

\author{
ANAClet PONS \\ Universitat de València
}

RESUMEN: Este ensayo pretende analizar el impacto de las nuevas tecnologías en la disciplina bistórica. Se parte de la constatación de que revolución informática ha modificado la técnica de transmisión de los textos, el soporte en que se comunican y los hábitos de lectura. Pero, además, trata de evaluar en qué medida puede cambiar otros elementos que se consideran fundamentales. Esas posibles modificaciones serían variadas. Por un lado, afectaría al tipo de fuente y, en cierta medida, al método crítico con el que los historiadores abordamos cualquier tipo de documento. Por otro, trastocaría también el concepto de autoría, no sólo porque muchos de los nuevos textos que existen carecen de firma reconocible, sino porque buena parte de ellos son fruto de reelaboraciones colectivas, disolviendo así el concepto fuerte de propiedad al que estábamos acostumbrados. Finalmente, se modificaría la escritura bistórica, pasando de una de tipo jerárquico y cerrado a otra mucho más desordenada y abierta.

Palabras Clave: Historia. Historiografia. Hipertexto. Web. recursos de internet.

ABSTRACT: This essay attempts to assess the impact of the new technologies on the discipline of bistory. It starts from the assumption that the revolution in information technology has altered the way in which texts are transmitted, the medium in which they are made available, and the ways in which they are read. Moving on, this essay tries to evaluate how far it might affect other fundamental ideas. The changes are various. On the one hand, it could have an effect on the type of source, and to a degree on the critical method with which historians approach whatever type of document. On the other hand, it could also undermine the notion of authorship, not only because many of the new texts in existence lack any recognisable signature, but also because many of them are the product of collective reworkings, which further dissolves the deeply-rooted sense of ownership we are accustomed to. Finally, it could

1 Dada la rapidez con la que muta este munfo virtual al que nos referimos, convendrá señalar que este texto fue elaborado en mayo de 2005 y que, por tanto, algún url puede haber quedado obsoleto o haber desaparecido. 
bring about changes to the way history is written, making it much less hierarchical and closed and much more open and untidy.

KEY WORDS: History. Historiography. Hypertext. Web. internet resources.

«Where do you find history?», I imagine asking the students of the future.

«On the Web», they answer.

«How do you get at it?»

«By surfing»

«What method will you use to write your paper?»

«Access, download, hyperlink and printout»

Such thoughts touch off Luddite fantasies: smash all the computers and leave the Internet to drown in the ocean of its own junk. But that way madness lies, and my students have taught me that, if handled with care, the Internet can be an effective tool.

Robert Darnton, No Computer Can Hold the Past

Las palabras del celebrado historiador norteamericano Robert Darnton proceden de una evidencia incontestable, aquella según la cual eso que denominamos internet ocupa un lugar cada vez más importante en los distintos ámbitos de nuestra vida cotidiana, ya sea en nuestros hogares, en el mundo de la empresa, en el de la administración y, desde luego, en el universo docente e investigador. Algunos de nosotros, así como todas las instituciones académicas a las que pertenecemos (universidades, departamentos, asociaciones, etcétera), tienen ya lugar propio en ese firmamento virtual: allí se almacenan programas de asignaturas, lecciones, convocatorias, noticias, boletines y un sinfín de variados recursos. Nos hallamos, pues, ante un medio, una tecnología, que se ha impuesto con gran celeridad en todos los ámbitos como instrumento poderoso de comunicación, un instrumento que permite poner a nuestra disposición una gran cantidad de información a bajo coste. Por eso, quien quiere conocer cuando murió Kant, cuando nació Darwin, cuáles son los principales fenómenos de la revolución francesa o cuáles los índices demográficos o industriales de Kenia opta habitualmente por conectarse a internet. Un buen motor de búsqueda y cierta experiencia en separar la paja del grano pueden ofrecernos una respuesta en segundos a todos esos interrogantes y además podemos copiarla y archivarla en nuestro ordenador. Así pues, esta especie de red se impone, ya sea como instrumento publicitario, ya como fórmula educativa a distancia o ya como simple recurso informativo. El desarrollo es además exponencial y sus posibilidades teóricamente ilimitadas. Evidentemente, no es ninguna panacea, pues también se corre el riesgo de la desorientación y la pérdida de tiempo. Pero eso se supone que afecta en menor medida al historiador. Se sospecha que ese riesgo se reduce 
en nuestro caso en la medida que sabemos exactamente lo que buscamos y a partir de qué herramienta podemos obtener la información requerida.

De todos modos, no todo son parabienes y cortesías, pues bien podría decirse que los historiadores hemos tomado el tren en marcha, con un cierto retraso respecto de lo que les ha ocurrido a las ciencias sociales y sobre todo a la ciencia natural. Pero como consuelo podemos considerar que tal demora acaso sea ventajosa, al menos en la medida de que ahora el coste de convertirse en un investigador avezado en estos menesteres es menor. De hecho, informatizarse está hoy al alcance de todos y, en nuestro ámbito, se produce casi como efecto inducido por la competencia que demuestran quienes nos rodean, en especial los estudiantes. Por tanto, no debemos buscar ninguna coartada evasiva. Quedarse de espaldas a internet y a la informática supondría quedar probablemente desconectados del desarrollo actual sufriendo así una importante pérdida profesional. A la inversa, tampoco conviene exagerar, dado que un uso desmandado de tales instrumentos, sin el conveniente sentido crítico, puede conducir a una cierta uniformización de pensamientos y productos. En esto último se supone que jugamos de nuevo con ventaja en la medida en que éste es precisamente parte de nuestro trabajo, pues nuestra disciplina se basa en la crítica y el cuestionamiento perpetuos.

Partamos, pues, de la constatación de que este nuevo medio ha venido para quedarse y que su importancia está fuera de toda duda. En ningún caso podemos calificarlo de marginal. Así pues, hemos de asumir que nadie puede obviar la transformación sustancial que ha supuesto, ya sea en relación con las estrategias y técnicas comunicativas, ya con el nuevo tipo de acceso a la documentación, ya con la forma distinta de presentar los resultados de la investigación o ya con la forma en que permite compartir las experiencias y los problemas. Si estos cambios van a modificar la tradición plurisecular (la de la cultura libresca) es harina de otro costal, y también lo es cómo se producirá, pues tal presunción despliega un buen número de interrogantes que no podemos despejar aquí. En ese sentido, son muchos quienes opinan que este nuevo instrumento va a cambiar algunos de los elementos fundamentales del quehacer histórico. Por un lado, el tipo de fuente y, en cierta medida, el método crítico con el que los historiadores abordamos cualquier tipo de documento. Por otro, trastocaría también el concepto de autoría, no sólo porque muchos de los nuevos textos que existen carecen de firma reconocible, sino porque buena parte de ellos son fruto de reelaboraciones colectivas, disolviendo así el concepto fuerte de propiedad al que estábamos acostumbrados. Finalmente, se modificaría la escritura histórica, pasando de una de tipo jerárquico y cerrado a otra mucho más desordenada y abierta.

En lo referente a todas estas cuestiones, acaso haya sido el historiador francés Roger Chartier quien mejor las haya tratado, al menos dentro de nuestra comunidad académica. A su modo de ver, es evidente que la revolución informática ha modificado la técnica de transmisión de los textos, el soporte en que se comunican y los hábitos de lectura. Se abriría así una era de coexistencia entre la escritura manual, la impresa y la electrónica. Ahora bien, se pregunta, ¿hay que pensar que nos hallamos ante una mutación técnica comparable a la 
que supuso la invención de la imprenta a mediados del siglo XV? ¿Debemos relacionarla con una «crisis» que sería, al mismo tiempo, la del libro, de la lectura y de la edición? ¿O acaso no hay que considerarla más bien - concluyecomo una redefinición de las relaciones con la cultura escrita, caracterizada por la sustitución de los objetos impresos que fueron y son aún los nuestros (el libro, la revista, el diario) por el texto electrónico, en todas sus formas?

Si se acepta este último diagnóstico, nos dice Chartier, hay que recordar que el mundo occidental conoció una mutación semejante cuando el códice, es decir, el libro manuscrito compuesto de hojas plegadas, ensambladas y encuadernadas, suplantó, paulatina pero inexorablemente, el rollo de papiro. La invención del códice, de la paginación y de los índices instituía una relación inédita entre el lector y el texto, al mismo tiempo que permitía gestos imposibles con el rollo de papiro como, por ejemplo, escribir mientras se leía, hojear un libro o encontrar rápidamente un pasaje en particular. La revolución del presente sería, pues, de la misma importancia pero aún más radical, puesto que modificaría a la vez la técnica de transmisión de los textos, el soporte de su lectura y sus posibles usos. Pero, al igual que la revolución del códice en la Antigüedad se prolongó a lo largo de varios siglos, es probable que ahora asistamos a una coexistencia durable, pacífica o conflictiva, entre varios modos de producción y de reproducción de lo escrito (lo escrito a mano, lo impreso, el texto electrónico) y entre varias formas de «libro» ${ }^{2}$.

Pero esta es sólo una de las actitudes posibles y no todos la compartirán. En ese sentido, quizá fuera conveniente señalar que el nuevo medio ha generado dos tipos enfrentados de actitud. Por un lado, el escepticismo (cuando no la resistencia luddita), primero respecto del ordenador y luego en relación con la red, algo que se incardina dentro de un contexto más general de crítica al impacto de las nuevas tecnologías. Por otro, el entusiasmo tecnológico, el saludo encomiástico a una realidad que daría por terminada la vieja cultura y todos sus postulados, algo que permitiría nuevas formas de autoridad, más democráticas, bipertextuales. No obstante, no se puede negar que la actitud escéptica se ha ido erosionando, pues muy pocos muestran aún una actitud de rechazo, lo cual resultaría muy embarazoso ante la evidencia de las ventajas que su uso conlleva. De todos modos, el espejismo se ha convertido a menudo en perplejidad, en preguntarse por la red como instrumento de investigación, por los nuevos modos de publicación, por

2 Como suele ser costumbre, las reflexiones de Chartier sobre el particular se han difundido reiteradamente y por diversos medios. Por lo que se refiere a la versión española, se pueden hojear en el capítulo titulado «iMuerte o transfiguración del lector?» que se incluye en su libro Las revoluciones de la cultura escrita, Barcelona, Gedisa, 2000, págs. 101-120. El texto reelaboraba la conferencia presentada ante el XXVI Congreso de la Unión Internacional de Escritores celebrada en Buenos Aires en mayo de 2000. Con el mismo título se publicó en el número 116 de la revista argentina Novedades Educativas (agosto de 2000) y en el número 239 de la Revista de Occidente (marzo de 2001), aunque esta edición no sea la última. En cualquier caso, y para no cansar, cabe decir que en ese año de 2001 la Biblioteca Virtual Miguel de Cervantes incluyó en su catálogo otra versión, ahora digital: http://www.cervantesvirtual.com/historia/CarlosV/recurso1.shtml. 
la calidad de lo que se edita, etcétera. Y a la perplejidad se une también la tolerancia, sobre todo ante la imposibilidad de gobernar o controlar un medio que precisamente se caracteriza por todo lo contrario. No obstante, una suerte de tolerancia pasiva, acrítica, puede que no sea buena consejera, puesto que el mundo telemático se basa en parámetros nuevos que hemos de evaluar para poder usarlos con sentido disciplinario, metódico.

Por otra parte, y en buena medida, esa exaltación o la tolerancia pasiva provienen de la creencia de que la revolución electrónica parece prometer un acceso universal a la cultura escrita, olvidando que eso es algo que, como contrapartida, puede profundizar las desigualdades, geográficas o sociales. Existe de hecho el riesgo de un nuevo "analfabetismo», definido no ya por la incapacidad de leer y de escribir, sino por la imposibilidad de dominar las nuevas formas de la transmisión de lo escrito, que distan mucho de ser universales y gratuitas. Tanto los lectores potenciales de los libros electrónicos como los usuarios de internet sólo son aún, a escala planetaria, una minoría, algo muy grave si aceptamos que es técnicamente posible (y esa hipótesis es cada vez más real, como ha demostrado la empresa que gestiona el buscador Google 3 ) que todos los textos existentes, manuscritos o impresos, sean convertidos a formato electrónico. Además, como señalaba Chartier, esa posibilidad técnica no supondrá la muerte próxima del libro, de lo escrito y de la lectura. Entre otras razones porque la pantalla del ordenador no opone la imagen a la escritura, como lo hacían el cine o la televisión, sino que constituye un poderoso instrumento de difusión de la cultura textual, aunque de distinto signo. De hecho, no sólo son muchos los que usan la pantalla como paso previo a la impresión en papel, sino que las posibilidades que permite han multiplicado y dinamizado el mundo de lo escrito.

En suma, pues, no conviene exaltar los ánimos, De momento, las pautas disciplinarias se mantienen incólumes, a pesar de los anuncios más o menos apocalípticos de cambios inmediatos, y buena prueba de ello es que muy pocos textos de historia utilizan esos avances, y desde luego los libros académicos ni suelen tratar estas cuestiones ni acostumbran a incluir referencias a direcciones en la red ${ }^{4}$. No obstante, la cuestión es que, lo advirtamos o no, con internet

3 Al parecer, el proyecto de Google pretende digitalizar a lo largo de diez años quince millones de volúmenes, procedentes de los fondos de las universidades de Michigan, Stanford y Harvard, así como de la biblioteca pública de Nueva York y de la Bodleian de Oxford (http://print.google.com/). Como es sabido, la Unión Europea ha pasado de criticar el proyecto a promover uno semejante, con Jean-Noël Jeanneney al frente, reputado historiador y director de la Bibliothèque Nationale de France.

4 En España, quizá uno de los pocos casos sea el de PAssamar, Gonzalo: La historia contemporánea, aspectos teóricos e historiográficos, Madrid, Síntesis, 2000, nada comparable, por supuesto, a lo que puede ocurrir fuera de nuestras fronteras académicas. Tampoco hay nada semejante a un libro del tipo del que editan periódicamente desde 1997 David Trinkle y Scott A. Merriman, y cuya última edición de setecientas páginas y cd adjunto lleva por título The History Highway 3.0: A Guide to Internet Resources, New York and London, M.E. Sharpe, 2002. La propia editorial tiene versiones distintas referidas a la historia americana, a la europea y a la universal, 
también se hace la historia, lo cual quiere decir que se la escribe o que se convierte en fuente, aunque los historiadores no siempre sepamos qué hacer con esta nueva herramienta. Para ello, para aclarar su significado, quizá convenga recordar algunos aspectos de su trayectoria y establecer los elementos fundamentales que la integran. Es decir, intentar establecer los rudimentos básicos que, a la postre, nos permitan evaluar sus contenidos. Como dijo Umberto Eco en cierta ocasión, «internet es un equivalente virtual del Universo. Como en el Universo, hay bosques y ciudades. Desde Estados Unidos a Burkina Faso, hay de todo en internet. Las webs nazis, aquellas que quieren venderte cualquier cosa y las porno. iHasta los textos del Concilio de los padres de la Iglesia! Es increíble, están allí, cuando antes no los consultaban más que un puñado de sabios en bibliotecas especializadas. El gran problema de internet es el filtro. Yo sé distinguir una web de un loco de otra seria, pero para un joven estudiante es peligroso» 5 .

\section{UN POCO DE HISTORIA}

Aquello que denominamos World Wide Web (o simplemente web o internet, dicho de forma coloquial y reductora) remite en última instancia a dos cosas diversas. Por un lado, nos referimos con ese término al lenguaje con el que introducimos y estructuramos la información que ofrecemos. En este caso, lo común es hablar de html (HyperText Markup Language), aunque existen otros formatos, como el xhtml (Extensible HyperText Markup Language). Por otro, lo utilizamos también para describir lo que se designa como interfaz, eso que, por ejemplo, nos permite navegar y buscar a través de determinados protocolos, sobre todo el http (HyperText Transfer Protocol), es decir, el estándar utilizado para transferir todo tipo de documentos. Así pues, dada esa diferencia, puede que una cosa y la otra no se den al unísono. De hecho, con nuestro navegador podemos acceder a textos cuyo formato no sea hipertextual ni hayan sido creados con ese lenguaje. Asimismo, y por el mismo motivo, podemos utilizar nuestro editor de textos habitual para crear un documento btml que no tenga como finalidad ser publicado en internet. Estos dos elementos son, pues, los que definen la novedad introducida por la web, una novedad que cambió el mundo internet. De hecho, como recordaran los más avezados, este último ya existía con anterioridad, pero sus herramientas (correo, ftp, telnet) se basaban sólo en texto.

\footnotetext{
todas ellas publicadas en 2002, y prepara una nueva para dentro de poco y prepara una nueva para dentro de poco.

5 Estas declaraciones proceden de la entrevista que le realizaron Florent Latrive y Annick Rivoire con motivo de la presentación del «Manual interactivo del saber» y se publicaron en Libération («L'écrivain et les souris savantes, Umberto Eco lance le Manuel interactif du savoir») y en El Periódico el 7 de enero de 2000.
} 
Ahora bien, lo que hace que todo ello funcione tal y como estamos acostumbramos a verlo, lo que hace que la web sea lo que es hay que encontrarlo, por simplificar las cosas, en el url (Uniform Resource Locator). El consorcio mundial (W3C) que intenta liderar el desarrollo potencial de este mundo posible lo define del siguiente modo: "A short string that uniquely identifies a resource such as an html document, an image, a down-loadable file, a service, or an electronic mailbox» ${ }^{6}$. Esta definición nos permite advertir la importancia de otros dos elementos. En primer lugar, los recursos: la red de datos, documentos, objetos o servicios que podemos identificar y a la que podemos acceder mediante ese $u r l$. En segundo término, el enlace: el mecanismo que conecta distintos recursos desde el interior de uno de ellos, es decir, una referencia a otro documento o a otro objeto que se puede hallar en el mismo lugar o en otro muy distante. En suma, pues, es imposible imaginar la web sin esos identificadores y sin los navegadores que sepan interpretarlos. Y ello a pesar de que estos últimos pueden utilizarse para cosas que no son exactamente lo mismo, ya sea para jugar o para chatear.

Así pues, las posibilidades de esta nueva realidad son múltiples y su uso variadísimo. Sin embargo, nos centraremos aquí en las implicaciones que para nuestra disciplina puedan tener los dos últimos: los recursos y la hipertextualidad. En ese sentido, decía Graeme Davison, el reputado historiador australiano, que "only in the 1980s and 1990s has the industrial revolution finally arrived in academia. Now, as we contemplate the approach of the virtual university, we know something of the mingled excitement and anxiety that gripped the handworkers and artisans of the newly mechanised trades of the first industrial revolution ${ }^{7}$. Sin embargo, añadía, los académicos estamos preparados para esta revolución, pues no en vano llevamos años aplicando una forma primitiva de hipertexto (la nota a pie de página), de modo que el proceso clásico de escritura y el de lectura nos tendría preparados, con la mente dispuesta para este nuevo cambio. Puede que Davison esté en lo cierto, pero quizá sea una actitud complaciente y remisa en exceso. $\mathrm{Y}$ puede que lo sea porque, como parece evidente, existen diferencias sustanciales entre las fuentes clásicas y los nuevos recursos virtuales, entre la escritura histórica textual y las nuevas formas. De hecho, si este artículo estuviera escrito en hipertexto, no habría notas, en este punto podría conectar con un documento externo o con parte de él y quizá el lector considerara que ese otro tiene un mayor interés y puede así, finalmente, que ya no continuara con la lectura inicial y la abandonara en beneficio de otra distinta.

6 La referencia se puede consultar en diversas partes, una de ellas es la página de este organismo: http://www.w3.org/TR/di-gloss/. Como se puede observar allí, el URL se confunde con ese otro acrónimo llamado URI (Universal Resource Identifier).

7 Davison, Graeme: «History and Hypertext", The Electronic Journal of Australian and New Zealand History (agosto de 1997): http://www.jcu.edu.au/aff/history/articles/davison.htm. 


\section{Recursos: la palabra mágica ${ }^{8}$}

Dentro de la terminología propia de la red, ésta es sin duda la palabra más evocadora. La web se nos ha presentado como una fuente inagotable de recursos, y su riqueza parece tanto más fascinante cuanto mayor énfasis han puesto los medios de comunicación en señalar que el acceso a ella es la clave de todo, que quien quede al margen perderá el tren del conocimiento. De hecho, es tal la aglomeración informativa que ofrece que resulta imposible describir razonablemente su contenido, de modo que sólo vale explorarla. No es extraño, pues, que quienes la designan usen reiteradamente todo tipo de metáforas que aluden a ese significado: navegar, explorar, universo, telaraña, etcétera. La conclusión es que creemos que en la red lo encontraremos «todo», cuando la realidad es que hallaremos "de todo", y ésta es una diferencia sensible9. Más aún, ese «de todo» está sujeto a ciertas restricciones de acceso. Primera: el volumen. El número de páginas o sitios disponibles es sencillamente exorbitante, de forma que ese exceso de ruido informativo produce insatisfacción y desorientación. Segunda: la tipología. Buena parte de la información disponible está compuesta de datos en bruto, sin un tratamiento adecuado. Tal presentación supone que desconozcamos en general los criterios de elaboración y que, por tanto, no podamos evaluar a simple vista su calidad. Ocurre en ese punto que estamos acostumbrados a la producción libresca, donde existen distintos indicadores externos que nos ayudan a valorar un determinado texto, y eso no suele ocurrir en el formato telemático ${ }^{10}$. Tercera: el idioma. Como es de sobra conocido, la mayor parte y la más sustanciosa de la información disponible está en inglés, lo cual significa dos cosas: por un lado, que el desconocimiento de esta lengua o la falta de unos mínimos rudimentos de lectura reduce enormemente su aprovechamiento y, por otro, que esos contenidos se corresponden con las necesidades de usuarios mayoritariamente americanos o anglosajones. Finalmente, los medios. Aunque entrar en internet es relativamente sencillo y económico, esa posibilidad no está tan extendida como debiera, de forma que su uso es más restrictivo de lo que pudiera parecer. Además, cada vez es más costosa económicamente: dada la evolución de las nuevas tecnologías y sus costes económicos, estamos asistiendo a un aumento de los servicios de pago que quizá afecte bien pronto a sitios que hoy consultamos gratuitamente.

8 Ejemplos de lo que sigue se pueden repasar en mi propia página (http://www.uv.es/ apons/ uno.htm) y en muchas otras, como es obvio.

9 Véase a este respecto la obra de MINUTI, Rolando: Internet et le métier d'historien, París, PUF, 2002. Existe una versión italiana que se puede consultar libremente: «Internet e il mestiere di storico. Riflessioni sulle incertezze di una mutazione», Cromobs, núm. 6 (2001), págs. 1-75: http://www.cromohs.unifi.it/6_2001/rminuti.html.

${ }_{10}$ Por supuesto, internet cuenta también con signos externos evidentes. Sabemos, por ejemplo, que se trata de una institución educativa (por el sufijo edu) o comercial (com) y existen algunos evaluadores externos de cierto prestigio. Por citar procedencias diversas, véase: http://www.historyguide.de/; http://album.revues.org; http://www.humbul.ac.uk/. 
Ahora bien, más allá de las restricciones, algo que no puede ponerse en duda es que, como hemos dicho, el crecimiento de los recursos es vertiginoso, incluso podemos convenir en que es difícil de cuantificar y por eso mismo de ordenar. De ahí la importancia de conocer el medio y desarrollar frente a él una actitud analítica de carácter crítico, pues cualquier mirada pasiva puede conducir a la desorientación más absoluta. Tomémoslo, pues, como un territorio a explorar, eso sí, extraordinariamente heterogéneo. No intentemos aplicar sin más los mecanismos mentales que tradicionalmente hemos usado para otras fuentes del saber, pues eso sólo provocará insatisfacción y una fuerte sensación de pérdida de tiempo. Todos hemos experimentado la desorientación que resulta de introducir una palabra en cualquier buscador y observar que se obtienen miles de respuestas sin criterio de relevancia. Afortunadamente, la práctica en el uso de la red y la aparición de motores de búsqueda más refinados están limando estas asperezas. Aún así, eso requiere tiempo y esfuerzo, no siempre recompensados, no sólo porque la red cambia continuamente y hay cosas que ayer anotamos y hoy ya no existen y a la inversa, sino porque puede que al final de un laborioso proceso de recopilación lleguemos a la conclusión de que lo más relevante también lo hubiéramos obtenido (y más rápidamente) en cualquier biblioteca. Eso quiere decir que la web no siempre es el mejor camino para llegar a un punto determinado, a veces es incluso un itinerario más tortuoso. De todos modos, parece imprescindible, tanto en lo referente a la difusión de conocimientos más o menos genéricos cuanto al acceso a textos y fuentes de referencia. Veamos ambas cosas por separado.

Si partimos de la desorientación que provoca, se entenderá que surja la necesidad de practicar una suerte de trabajo de regulación del tráfico en la red. Además, tal tarea no puede realizarse ajena a la comunidad académica, pues de lo contrario corremos el riesgo de que ésta acabe por desechar la red como instrumento válido para su actividad. Precisamente lo que distingue a los colectivos de profesionales, incluido el de los historiadores, es su función disciplinaria, sus mecanismos de reconocimiento, valoración y juicio sobre los asuntos que les afectan y éste es uno de ellos. Eso es tanto más importante en el caso que nos ocupa en la medida en que ese «de todo» que contiene la red está profundamente desequilibrado. Junto a recursos de alto valor, lo habitual es que los contenidos sean resultado de aficiones varias, de la recopilación de eventos memorables, de biografías ilustres o genealogías particulares, de misterios o secretos o incluso como juego interactivo. Por no hablar de las páginas claramente propagandísticas, lugares donde se pone de manifiesto uno de los rasgos de este mundo virtual, el uso marcadamente instrumental del conocimiento histórico ${ }^{11}$.

11 Véase el texto de AвватіSTA, Guido: «Problemi di valutazione delle risorse telematiche per la ricerca storica», workshop La valutazione delle risorse digitali: biblioteche ibride e studi storici, coordinado por Guido Abbattista y Riccardo Ridi (Florencia, 31 mayo - 1 junio de 2001), Dipartimento di Studi storici e geografici, Università di Firenze, 2001: http://www.dssg.unifi.it/_storinforma/ Ws/biblio/Abbattista - Valutazione.rtf. El autor, nos ofrece, además, los criterios que podrían 


\section{a) Los buscadores restrictivos}

Es lógico, pues, que los propios historiadores hayan intentado elaborar medios de control. Eso fue lo ocurrido, por ejemplo, con el buscador Argos, que era fruto del trabajo de la Universidad de Evansville y que contaba con el reconocimiento de la comunidad académica, puesto que cada uno de los enlaces que contenía era evaluado y supervisado por un consejo editorial del que formaban parte conocidos especialistas. Los americanos, tan dados al uso de los acrónimos, dieron en llamar a esta herramienta LASE (Limited Area Search Engine). Es decir, un buscador temático o limitado, diseñado en esta ocasión para abarcar la información disponible sobre el mundo antiguo y medieval. La intención era, pues, convertirlo en una fuente académicamente controlada para estudiantes y profesores. El modelo tuvo cierto éxito, pero finalmente ha adquirido una de las particularidades de internet, la ausencia. Si alguien tiene la curiosidad de visitar el proyecto, la institución que lo albergaba le informara de que «have been taken offline due to a lack of resources needed to keep them running and up to date». Hay que hacer notar que esta eventualidad no es una excepción o un error en la cita, sino que forma parte sustancial de la forma en la que este mundo se nos presenta, parte de su descontrol. Así, lo mismo se puede decir del buscador italiano Onoria, dedicado al medioevo italiano, y que era heredero de otros dos (Placidia y Galla) centrados sobre la historia y las humanidades. Cualquier búsqueda que se realice devuelve un mensaje descorazonador: «Spiacenti... Onoria è in modalità di manutenzione. Tornerà in servizio entro dicembre 2003 ${ }^{12}$.

Por fortuna, Argos u Onoria no eran los únicos buscadores de este tipo, aunque no abundan. Para la historia en general existe uno francés denominado Inextenso, mutación de otro anterior que se llamó Aleph (puesto en funcionamiento en marzo de 2001 por Revues.org, la federación de revistas de ciencias sociales y humanas). Éste combina las características de los motores generalistas con su voluntad de centrarse exclusivamente en las ciencias sociales, a la vez que utiliza controles semejantes a los dispuestos por Argos, aunque está más cerca del formato Yahoo, pero sin sus defectos (si preguntas por Napoleon no incluirá en sus respuestas las ciudades o los hoteles de tal nombre). Así, sus responsables lo denominan también un LASE, dado que se especializa en ciencias humanas y sociales francófonas. Su problema actual es que tiene (relativamente) pocas páginas catalogadas, aunque una de sus partes indexa varias decenas de miles de artículos procedentes de más de doscientas revistas académicas. Además, tiene otras

\footnotetext{
servirnos para valorar de forma disciplinaria los distintos recursos disponibles. Un texto similar es el de F. Chiocchetti, «Le guide alle risorse storiche online: una rassegna critica», Cromobs, núm. 7 (2002), págs. 1-22: http://www.cromohs.unifi.it/7_2002/chiocchetti.html.

12 Dado el objeto que nos ocupa, abrumar con referencias resultaría un sinsentido. Basta con utilizar un buscador para llegar a lo descrito. En este caso, las referencias proceden del momento en que se realizó este artículo, en mayo de 2005.
} 
ventajas aparentes: indican sus promotores que las páginas han sido seleccionadas por su calidad, su riqueza y el rigor de su contenido científico; absorbe de forma exhaustiva todos los contenidos de esas páginas; y se actualiza mensualmente. Así, cualquier texto que incorpora, lo memoriza por completo.

\section{b) Los catálogos temáticos.}

En cualquier caso, ese modelo restrictivo de buscador aún no se ha generalizado y no parece que consiga imponerse. De ahí, pues, el éxito de los catálogos de recursos temáticos, una especie de librerías digitales, cuyo propósito no es cribar toda la red, sino seleccionar aquello que pueda tener mayor relevancia dentro de un área determinada. En estos casos obtenemos una alternativa al desorden y a la redundancia, que en general se acompaña de comentarios o indicaciones sobre cada uno de los lugares seleccionados. Estas iniciativas son, por otra parte, cada vez menos impresionistas, puesto que se han desarrollado diversos mecanismos para evaluar los recursos que contiene la red. En el futuro, quizá la aplicación de estos criterios conduzca a una especialización en la elaboración de páginas web, recortando ese individualismo y voluntarismo que hoy imperan. En la práctica, y si observamos el modelo americano, el más desarrollado, podemos concluir que el mantenimiento de páginas web está ya en manos exclusivamente de los servicios bibliotecarios de las universidades o de otros centros oficiales de la administración. Todos, pues, parecen asumir que ésta es la mejor opción: dejar en manos de profesionales esa ordenación del caos, esa guía sin la cual todo es un rumor informativo. Su tarea, pues, ha de ser la de fijar criterios uniformes de relevancia sobre la base del contenido académico de los lugares examinados. En la actualidad, dentro de lo que estos catálogos de recursos temáticos, destaca, por ejemplo, la $W W W-V L$ History Index, el más veterano de los catálogos existentes, pues fue iniciado por Tim Berners-Lee, uno de los padres fundadores de este mundo virtual. En cuanto al contenido, sus criterios quizá no sean tan selectivos como los establecidos en el modelo anterior de buscadores, pero cada rama está mantenida por un especialista reconocido que garantiza la relevancia de lo que se agrupa. De todos modos, se trata de un modelo federal, descentralizado, con un equipo heterogéneo que no proporciona coherencia, es decir, un modelo que está en consonancia con las características propias de la red y que ofrece una solución muy común en estos casos. Sea como fuere, estas páginas son un instrumento esencial para empezar una navegación ordenada por el caudal de los recursos que ofrece la red. Además, sus subdivisiones son muy útiles, tanto las referidas a los distintos periodos históricos como las geográficas ${ }^{13}$.

13 La página que corresponde a España, por ejemplo, está desarrollada y mantenida por Iñaki López Martín, que pertenece al Robert Schuman Centre for Advanced Studies del Instituto Universitario Europeo de Florencia: http://vlib.iue.it/hist-spain/Index.html. 
Estos últimos rasgos son precisamente los que explican el éxito de ese modelo, basado en la confianza que genera su estructura. No es, pues, extraño que esa fórmula se haya ido imponiendo, es decir, que hayan proliferado los lugares en los que cada disciplina y cada subárea están a cargo de académicos más o menos reconocidos. Es el caso de about.com, uno de los portales más visitados ${ }^{14}$. Por supuesto, este parece ser el sistema con mayor proyección, aunque no sustituirá por completo a la ingente cantidad de páginas personales, muchas de ellas realizadas por colegas nuestros, que ofrecen sus propias recopilaciones con medios y resultados más modestos.

\section{c) La búsqueda aleatoria}

De todos modos, por muy ordenados que estén los recursos que necesitamos, eso no evitará los problemas: la falta de originalidad, la información reiterativa, la uniformidad, etcétera. Pero eso no debe desalentarnos. Un recurso es aquello que nosotros calificamos de tal en relación con el problema o el asunto que tratamos. Por tanto, cualquier cosa (con las prevenciones necesarias) puede convertirse en material fértil. Algo que carece de originalidad desde el punto de vista de la investigación o simplemente del conocimiento, quizá tenga valor didáctico. Ahora bien, esta ordenación no la proporciona nadie, es algo que nosotros debemos introducir, de ahí la necesidad de un uso responsable de lo que la red nos ofrece. De hecho, aunque en principio todo nos fascina, cada uno de nosotros acude a la red buscando respuestas concretas a cuestiones particulares, y quizá en ese sentido sí que podamos tener una herramienta más precisa que otras que usábamos hasta ahora. Claro que para ello hay que saber utilizarla o ser ayudados por alguna orientación metodológica que aporte la comunidad académica a la que pertenecemos. El problema es, pues, transformar la información en conocimiento.

Supongamos, por ejemplo, que un docente va a explicar en su aula la figura de Napoleón. ¿Qué espera de la red? Dos cosas: le atrae tanto la posibilidad de obtener información sobre el tema cuanto la perspectiva de salir de su aislamiento y contactar con personas que le ofrezcan experiencias sobre cómo explicar esa materia. Así pues, espera que internet pueda facilitar a sus estudiantes diferentes perspectivas sobre el personaje, imágenes, una cronología de su vida, mapas que reproduzcan sus campañas. Claro que antes tendrá que preparar todo eso. Que sepa hacerlo, tenga tiempo y paciencia, es otro asunto. Lo primero es advertir que ese gran catálogo no está discriminado: todo lo que hay es

14 About.com no es un portal educativo, sino que pertenece a una conocida empresa americana de medios de comunicación, Primedia, y suele utilizar jóvenes licenciados para que evalúen los recursos recopilados. Si uno visita la sección de historia europea, por ejemplo, observará que está a cargo de Robert Wilde, BA en historia y MA en estudios medievales por la Sheffield University y de quien se dice que está preparando la publicación de su primer artículo académico. 
para todos. Los resultados de un buscador no diferenciarán grados de comprensión, no distinguirán lo que es adecuado para un especialista universitario, un profesor de secundaria o un estudiante. El diseño extenso, ampliable e imprevisible de internet es, pues, casi antitético a las necesidades algo discretas del caso que nos ocupa. Los sitios individuales de la web pueden, por supuesto, compensar algunos de los defectos de ese diseño. Una página se puede construir para resolver las necesidades exactas de profesores, proporcionando una cantidad de información cuidadosamente limitada, apropiada a los niveles de detalle y de edad requeridos, así como presentar sus contenidos como un todo dirigido a una actividad concreta, más que como ítems independientes. Sin embargo, pocos lugares han sido construidos de ese modo. En realidad, la mayoría de páginas se han rellenado con toda la información histórica posible en la creencia de que cuanta más se incluya, mayor probabilidad habrá de que todos encuentren lo que buscan. Tomemos cualquier motor de búsqueda: el resultado serán varios miles de referencias sobre Napoleon, lo cual hará sospechar de inmediato a nuestro profesor que esa herramienta no está diseñada para favorecer sus necesidades.

Supongamos que hemos usado un buscador generalista como Yahoo o Google, por citar los más habituales, y que hemos acotado un poco más la consulta indicando que estamos interesados en «Napoleon Bonaparte». Pues bien, obtendremos entre seiscientas y ochocientas mil respuestas, según el caso, de las que alrededor de treinta mil contienen información en español. Así pues, una cantidad de información ingente y descontrolada, a pesar de que se indique que los resultados se organizan por relevancia (de mayor a menor número de visitas o de enlaces desde otros lugares) o que se evitan las reiteraciones. De ese modo, el problema radica en cómo encontrar algo que nos sirva, presumiendo que quizá exista lo que necesitamos pero advirtiendo que somos incapaces de encontrarlo rápidamente. Y, de hecho, existe. Quizá si tuviéramos cierta experiencia hubiéramos acudido directamente a determinados organismos que proveen de excelentes modelos sobre cómo organizar los materiales educativos que podemos utilizar los historiadores. En el caso de Napoleón, puede que los productos de la PBS (la empresa televisiva que gestiona las cadenas públicas norteamericanas), los recursos de la Fondation Napoleon, las informaciones de la Napoleon Bonaparte Internet Guide o la página de las Napoleon Series hubieran bastado. Ahora bien, sin olvidar que, como señalábamos con anterioridad, los buscadores no evalúan contenidos, sólo proporcionan un enlace. De ese modo, la visita no nos aclarará de entrada, excepto en el caso de la empresa PBS, quién es el autor que figura, si es que lo hace, ni con qué fines se ha elaborado.

\section{d) Archivos y bibliotecas}

Sea como fuere, si bien la búsqueda de una información concreta requiere acudir a algún buscador para que nos facilite la tarea, existen recursos obvios 
para quien se dedique a la historia y éstos están ya recopilados, de modo que podemos acceder a ellos directamente sin pasar por aquellas herramientas de rastreo. Son, claro está, los libros y los documentos almacenados en los archivos. Recordemos, las palabras de Robert Darnton respecto a los primeros: «La biblioteca pública de Nueva York ofrece tanta información a nivel electrónico a lectores de todo el mundo que cada mes se registran diez millones de entradas en su sistema de cómputo, en comparación con los 50 mil libros que se prestan en la sala de lectura ubicada en la calle 42. Al parecer, todo está digitalizándose y cada dígito se está uniendo a todos los demás por medio de hipervínculos. Si el futuro nos depara periódicos sin noticias, revistas especializadas sin páginas y bibliotecas sin muros, ¿qué será del libro tradicional? ¿Acaso la edición electrónica lo borrará de la faz de la Tierra?»15. En ese sentido, el acceso electrónico a los catálogos de las bibliotecas y a los repertorios bibliográficos constituye un instrumento excepcional. Además, no se trata sólo de localizar más rápidamente una referencia, sino que esta nueva catalogación permite aflorar una riqueza casi desconocida y encontrar textos que con anterioridad eran muy difíciles de situar. En ese contexto, la perspectiva que mayor fascinación ejerce es la de la posibilidad de tener acceso directo a los documentos históricos desde la pantalla de nuestro ordenador. Y hay que añadir que esta contingencia es menos remota de lo que pueda parecer, en la medida en que tal proyecto no obedece solamente a las necesidades de los investigadores, sino que responde a problemas referidos a la conservación y almacenamiento de los propios fondos

En realidad, todos esos cambios, en lo que se refiere a las fuentes que utilizamos, son de dos tipos y van más allá de lo apuntado por el historiador norteamericano en esta ocasión. En primer lugar, internet generaría información distinta, producida de forma diversa y difícilmente reducible a los parámetros tradicionales, una información alejada de los depósitos habituales, sin autoría definida, cambiante, etcétera. Es decir, lo que caracteriza a cualquier documento es su condición inmutable, el que no deba ser modificado, y su atribución a una persona o institución, así como a un contexto temporal concreto. En cambio, el documento electrónico es todo lo contrario, siendo susceptible de ser manipulado y alterado, de modo que exige nuevas formas de análisis. El mejor ejemplo quizá sea el del correo electrónico, que sustituye a la correspondencia escrita tradicional y que plantea problemas de primer orden a los historiadores.

En segundo término, este nuevo medio vendría a sustituir la fuente tradicional, digitalizándola, de modo que el contexto que le daba sentido y la propia materialidad que la definía quedarían alterados. Así, por ejemplo, y refiriéndose al proyecto de Google de digitalizar montañas de libros, el mismo Robert Darnton señalaba la pérdida que esa forma de presentación implicaría: si se

15 Estas palabras de Robert Darnton sobre la edición electrónica proceden de «The New Age of the Book», The New York Review of Books, vol. 46, núm. 5 (18 de Marzo de 1999), pp. 5-7 (hay traducción en «La nueva era del libro», Letra Internacional, núm. 62, mayo-junio, 1999, págs. 21-26, así como una versión electrónica en el núm. 350 de la revista mexicana etcétera: http://www.etcetera.com.mx/). 
observa la encuadernación y la calidad del papel de un libro - nos alertaba-, un investigador avezado es capaz de extraer información significativa acerca del período en el que fue publicado, de su editor y del público al que el volumen estaba dirigido. De ese modo, añadía, acaso andemos parcialmente desencaminados cuando nos mostramos convencidos del sentido de este cambio, al menos respecto de que todos los conocimientos estarán a nuestro alcance. Por otra parte, ésta no es una reflexión nueva, pues este celebrado historiador modernista ha insistido en diversas ocasiones sobre el significado de la edición electróni$\mathrm{ca}$, defendiéndola por cuanto mejoraría el proceso de la edición académica en todos los sentidos, pero advirtiendo los cambios que produciría, es decir, señalando que exigiría un nuevo tipo de lector y de lectura ${ }^{16}$.

La mayor novedad, pues, radicaría en última instancia en la ausencia física del documento. Es decir, estamos acostumbrados a usar una serie de técnicas y de procedimientos que están ligados a la presencia del documento, a su manoseo y a su contextualización documental (dónde se guarda, junto a qué otros documentos, etcétera). Eso es, pues, lo que se modifica, dando un paso más dentro de su carácter de representación, pero no sólo eso. No sólo se altera el uso que de él podemos hacer, sino la percepción que tenemos y la forma en qué lo leemos. Mientras la reproducción digital nos devuelva una imagen mimética del original, en la medida de lo posible, las modificaciones son parciales, pero su traducción a un lenguaje digital es un cambio radical: de la materialidad del texto, del orden del discurso, de los usos particulares, de los hábitos de lectura, etcétera. Por eso mismo, Roger Chartier concluía que la revolución del texto electrónico es un compendio nuevo y simultáneo de lo ocurrido en el pasado, es «al mismo tiempo una revolución de la técnica de producción y de producción de textos, una revolución del soporte de lo escrito y una revolución de las prácticas de lectura ${ }^{17}$.

Sea como fuere, la relación que mantenemos con el documento va a cambiar, puesto que se producirá una mediación mecánica. Frente a un texto físico impongo mi capacidad analítica, mi experiencia investigadora y todo un conjunto de técnicas que me permiten contextualizarlo e interpretarlo, y ello aunque utilice alguna mediación (reproducción en fotocopia, microfilm, facsímil, distinta edición, etcétera). El documento digital es más cambiante, incluso tenemos problemas para poder visualizar en nuestros ordenadores documentos que fueron confeccionados con procesadores de textos de hace diez años y que fueron almacenados en disquetes flexibles.

16 Las declaraciones de Darnton sobre el proyecto Google se publicaron en The New York Times, recogidas en un artículo titulado "Questions and Praise For Google Web Library» (18/12/2004). Véase asimismo la nota precedente.

17 Véase «¿Muerte o transfiguración del lector?», en Las revoluciones de la cultura escrita, op. cit., pág. 109. 


\section{LOS NUEVOS TEXTOS DIGITALES}

Como se ha dicho, hablar de internet significa, como ocurre con otros asuntos, referirse a dos aspectos inseparables: la forma y el fondo. Vayamos, pues a ello. Aquello que caracteriza de entrada este medio es el formato digital, es decir, se trata de un nuevo lenguaje para la transferencia de información. Y la condición que este último adquiere es, como se ha mencionado, la hipertextualidad. De hecho, todos sabemos que su nombre responde a tal particularidad: Hypertext Markup Language. Es decir, lo que denominamos página web es a grandes rasgos un archivo de texto creado a partir de un conjunto de códigos o marcas que definen su estructura y su aspecto. El resultado es un documento en el que el nuevo lenguaje no sólo introduce texto, sino que permite incrustar otro tipo de objetos: imágenes, sonidos y, por encima de todo, enlaces a otras páginas. Este hecho es tan significativo que merece tratarse con cierto detenimiento.

Lo primero que hemos de preguntarnos es si toda la información que nos ofrece internet tiene las mismas particularidades, y a tal demanda hemos de contestar que ese conjunto de documentos disponibles no tiene idénticos rasgos, pero que, aún así, comparte ciertos elementos que le diferencian de un texto impreso e incluso de uno creado dentro de un ordenador personal. Veamos todo ello aplicándolo al terreno de la historia, sin que ello signifique en ningún caso obviar cuestiones más generales.

Cuando vemos nuestro trabajo editado en forma de libro o, salvando las distancias, cuando lo creamos en cualquier editor de textos (listo para ser impreso), observamos que se trata de un documento estable, jerarquizado, con un orden fijo que nosotros le hemos dado y que nadie puede modificar, excepto a través de la lectura. Pues bien, estos y otros distintivos se pierden cuando decidimos introducir nuestro trabajo dentro de la red. Y ello a pesar de que, como hemos apuntado, son múltiples las formas con las que podemos publicar en internet ese material. La fórmula más elemental consiste en almacenar un escrito con el formato con que lo hemos elaborado (ya sea con extensión $t x t$, doc o $p d f$, por citar los más comunes) con la finalidad de que otras personas puedan visualizarlo tal y como nosotros lo hemos creado. Sin embargo, esta esperanza es completamente vana, puesto que desde el momento en que hacemos público nuestro archivo, se convierte en otra cosa y puede ser manipulado (cortado, copiado, pegado, enviado, eliminado) con fines totalmente ajenos a nuestro control y voluntad. Por tanto, al aparecer bajo un nuevo entorno sus condiciones originales se alteran sensiblemente. De hecho, lo lógico es que ese archivo acabe guardado en otro ordenador y que, desde ese preciso instante, sea ya propiedad de otro usuario, que hará con él lo que estime más conveniente.

Ahora bien, ya hemos indicado con anterioridad que la característica más relevante de los documentos digitales es su condición hipertextual. En este caso, aunque la apariencia pueda ser la misma, se le añade el hecho de estar construido con un nuevo lenguaje, hecho éste que agudiza todos los rasgos que 
habíamos predicado para el caso anterior. Así, por ejemplo, si la red otorga a cualquier documento una cierta inestabilidad, ésta es aún mayor si hablamos de un hipertexto. De todos modos, no se trata aquí de desgranar todas las implicaciones que se derivan de tal circunstancia, pero hay una muy importante que sí conviene señalar: nos hallamos ante un nuevo tipo de escritura, lo cual significa que se emplean otras formas de argumentación y un estilo distinto que, entre otras cosas, acentúa el trabajo colectivo.

Pensemos, por ejemplo, en las revistas académicas, editadas con una determinada periodicidad, con una coherencia temática, etcétera. ¿Qué es lo que le diferencia de una revista digital? Ante todo, el nuevo lenguaje del que hablamos, que permite introducir elementos adicionales al simple texto: podemos incorporar una entrevista, un mapa, una película, un cuadro, etcétera. Pero además, su dinamismo: desde el mismo momento en que se publica, los autores pueden ser interpelados sobre su trabajo, se pueden generar foros de discusión, etcétera. Por no hablar del coste, mucho menor. Es decir, todo esto es substancialmente nuevo y poco tiene que ver con la escritura tradicional. Así pues, aunque continuemos llamando revista a este tipo de publicación, lo hacemos así para etiquetar el nuevo producto con un término que nos es familiar dentro de la tradición, pero la fórmula es ahora distinta. Incluso la función de autor puede cambiar. Si nos tomamos en serio lo que realmente significa el código del hipertexto, el resultado incluirá una nueva forma de escritura y, dentro de ella, un determinado número de conexiones (enlaces) a otros autores $\mathrm{u}$ otros documentos, es decir, textos independientes dentro de nuestro texto.

Así pues, nos movemos entre una escritura textual, ordenada y jerarquizada, y otra hipertextual, más desarticulada y participativa. Piénsese en lo más evidente: en que el lector es activo construyendo su propio texto, moviéndose en su interior o modificándolo (copiando, cortando, pegando); incluso puede empezar en un texto y acabar en otro, habiendo desechado el primero. Todo eso es lo que ha hecho que determinados pensadores sientan corroborada su afirmación sobre el fin del autor y de la autoridad, así como de la fragmentación, por no hablar del carácter de construcción artificial de la escritura histórica. Y razón quizá no les falte si llevamos hasta sus últimas consecuencias este nuevo modo de escritura. Un texto clásico es lineal, uno donde el lector no debe perder el hilo de la lectura, con una serie de referentes claros que indican lo que va antes y lo que sigue, lo que hay más arriba y lo que viene más abajo, lo que está dentro y lo que queda fuera, etcétera. A pesar, pues, de la libertad del lector, el papel impone una disposición espacial de los fragmentos que fija el orden del discurso. El hipertexto, en cambio, no es lineal, sino desordenado, con distintas configuraciones potenciales que invitan ante todo al vagabundeo ${ }^{18}$. Todo ello es importan-

18 Véase el análisis de CLÉMENT, Jean: «Du text à l'hypertexte: ver une épistémologie de la discursivité hypertextuelle», en J.P. Balpe, J.P. Lelu y I. Saleh (coords.), Hypertextes et hypermédias: Réalisations, Outils, Méthodes, París, Hermes, 1995: http://hypermedia.univ-paris8.fr/jean/articles/ 
te y supone una alteración profunda, en la medida en que la desaparición de estos y otros referentes puede modificar aspectos importantes dentro de la narración histórica: la secuencia cronológica, las relaciones causa-efecto, las diferencias entre texto y contexto, centro y periferia, etcétera.

Ahora bien, ese es el horizonte de expectativas, porque hasta el momento las contribuciones históricas más relevantes que se presentan en la red reproducen los modelos clásicos, sin alterar lo más mínimo la estructura del discurso histórico habitual. Es decir, el carácter cerrado y jerárquico de la escritura histórica puede permanecer relativamente inalterable durante mucho tiempo si la red sólo se usa para reproducir en formato digital el texto escrito con otros medios.

Tampoco está claro que el uso del hipertexto tenga que producir necesariamente aquella desintegración y fragmentación de autor y texto de la que hablábamos. Claro que para que eso sea posible necesitaremos que el autor tenga una competencia mínima en el uso de las nuevas herramientas, no ya de los procesadores, sino sobre todo de los programas de creación de hipertextos. En ese sentido, dado que el núcleo de un hipertexto es el enlace, es ahí donde se condensan la mayor parte de los problemas planteados. Ante todo, cambia la relación clásica y secular que el historiador establece entre diversos textos. Un simple impulso del dedo sobre el ratón remite de forma rápida e inmediata a otro lugar y esa facilidad puede alterar el contenido de la cita. Así, se puede organizar de una manera nueva la relación entre la demostración y las fuentes, la argumentación y los criterios de prueba. Por otra parte, si remitimos al lector a un sitio externo a nuestro texto, entonces éste se convierte en el punto de partida de una nueva red de conocimientos o reflexiones ajena a la que hemos establecido $^{19}$. En ese sentido, se trataría de una nueva forma de escritura abierta, pues tanto su contenido como su estructura se alimentarían de fuentes externas, pero no sólo en cuanto esas fuentes contienen datos o confirman lo dicho, sino fuentes que por sí mismas pueden organizar la información de un modo distinto. En última instancia, pues, esa rapidez, esa inmediatez, el favorecer recorridos libres y subjetivos, el presentar conexiones sorprendentes o

discursivite.htm. Por otra parte, un ejemplo magnífico de ese tipo de escritura puede ser, por ejemplo, el trabajo de CRIPPS, Michael J.: «Between Linear and Nonlinear. The Research Essay as Hypertext», Enculturation, vol. 4, núm. 2 (otoño de 2002): http://enculturation.gmu.edu/4_2/ cripps/files/cccc_hyperessay_frameset.html.

19 En ese sentido, tal remisión es algo distinto de lo que suponen las citas a pie de página, uno de los pilares de la escritura histórica, que tienen por función bien otorgar legitimidad al texto con firmes apoyaturas documentales o bibliográficas, bien elaborar un conjunto de datos de referencia, bien refutar a otros especialistas, bien aclarar un aspecto particular o bien, por qué no decirlo, disponer de un recurso retórico y ampuloso. Así pues, la modificación es sustancial. Véase, el celebrado libro de Anthony Grafton sobre Los orígenes trágicos de la erudición. Breve tratado sobre la nota al pie de página, Buenos Aires, FCE, 1998. Bien es cierto, como dice este autor, que el destino de la nota ha sido infausto, no sólo por la reducción de su letra, siendo por haber sido relegada del pie de página al final del texto, incapaz como es de contener las exuberantes pruebas que a menudo deseamos exponer. 
enlaces inesperados, todo ello parece ir en detrimento del discurso reflexivo, estableciendo nuevas relaciones entre distintos hechos o procesos, distintas de las secuencias clásicas de tipo cronológico o causal.

En cualquier caso, como es obvio, el enlace no siempre funciona de forma unívoca ni tiene las mismas implicaciones. Por un lado, puede ser exclusivamente una forma de remitir al lector a la nota o a otro documento incluido en el mismo sitio. Es lo que se ha llamado la hipertextualidad débil, que no plantea ningún problema significativo. De hecho, el texto histórico, el ensayo académico, en definitiva, guarda ciertos paralelismos con las nuevas formas de escritura digital, de modo que el paso de la forma tradicional a esta otra no debería suponer grandes alteraciones formales. La presencia de notas y referencias diversas, la inclusión de apéndices, índices, listas, etcétera, así lo indicarían ${ }^{20}$. Por otra parte, puede enviar al lector a otros textos fuera de nuestro control, en otro lugar de la red, con lo que estaríamos ante un modelo de hipertextualidad fuerte. Es en este segundo caso donde los términos de individualidad y de autoridad o de control se prestarían a discusión. Como se ha señalado más arriba, con este tipo de escritura remitimos al lector a un sitio que tiene vida propia, que puede transformarse parcial o totalmente con el tiempo y que incluso puede desaparecer, con lo que nuestra referencia pierde su sentido originario. Así pues, a mayor grado de hipertextualidad, menor control sobre el texto que generamos.

En el caso de la disciplina histórica, la casi totalidad de los textos digitales han apostado por el modelo de hipertextualidad débil o bien por una solución mixta. El caso más destacado y celebrado es, sin duda, el de Robert Darnton y su famoso texto «An Early Information Society: News and the Media in Eighteenth-Century Paris». Conviene señalar, además, que se trata del ensayo que este historiador presentó en enero de 2000 ante la American Historical Association en su calidad de presidente saliente, una costumbre que se remonta a 1884, al momento fundador de dicha institución. Además, dado que durante su mandato había llevado a cabo una decidida política de apoyo a la edición digital, el artículo venía a constituir una muestra de su voluntad de, por decirlo así, predicar con el ejemplo. Su presentación y el impacto que obtuvo sirvieron, asimismo, para dar el envite definitivo a la nueva versión digital de dicha asociación y de su carismática revista, la American Historical Review, hasta el punto que la versión electrónica de dicho texto fue escogida para inaugurar ese cambio ${ }^{21}$.

Este artículo, como su propio discurrir nos muestra, ofrecía dos niveles de lectura distintos. Por un lado, se trataba de un texto clásico, siguiendo las con-

20 Es la idea que defiende, por ejemplo, Solli, Arne: «Hypertext 'papers' on the Web: Students confront the linear tradition?», en The Journal of the Association for History and Computing, vol. I, núm. 2. (noviembre de 1998): http://mcel.pacificu.edu/JAHC/articlesI2.htm.

21 Annual address of the president of the American Historical Association, Chicago, 5 de enero de 2000: http://www.historians.org/info/AHA_History/rdarnton.htm. Ese mismo año sería publicado en la American Historical Review, vol. 5, núm. 1, págs. 1-35. Existe una versión castellana en la recopilación de ensayos titulada El coloquio de los lectores, México, FCE, 2003, págs. 371-429. 
venciones habituales del discurso histórico, con la particularidad de estar producido en este otro lenguaje digital. Por otro, ofrecía algunos de los elementos característicos de la hipertextualidad, pues además de las consabidas notas a pie de página, incluía gráficos, ilustraciones, documentos de archivo, mapas digitales del París de la época, de forma que el lector podía localizar, por ejemplo, los cafés a los que acudía la policía para informarse sobre actividades subversivas, así como los informes policiales obtenidos, reconstrucciones sonoras de canciones que difundían noticias políticas y, finalmente, la posibilidad de participar en una discusión en línea con el propio autor en la segunda quincena de marzo de aquel año $2000^{22}$. Es decir, se trataba de un texto moderadamente abierto, de una hipertextualidad prudente. Robert Darnton decía elaborar un cibertexto, pero en realidad todo el contenido estaba jerárquicamente controlado, de modo que el lector no podía salir (escapar) del ensayo, pues las referencias no eran realmente externas, dado que ese exterior quedaba dentro. Se podía ir del párrafo a la canción, y escucharla, o al mapa, y pasear por París, pero la melodía o el plano devolvían irremisiblemente al texto escrito. Por eso mismo, cuando el ensayo se publicó en la su versión papel de la American Historical Review, la pérdida apenas fue sentida ni su sentido alterado.

Más aún. Aquella versión dinámica existió cuando la web de la citada asociación estaba albergada en la Indiana University, que aún es su sede editorial23. Cuando se creó la nueva ubicación, el artículo pasó a estar restringido, a través de la American Historical Review, de modo que sólo los afiliados podían consultarlo libremente. Ese cambió, además, supuso la pérdida (¿momentánea?) de aquel aparato digital (mapas, canciones, etcétera ${ }^{24}$. De ese modo, no podemos recuperar ahora mismo la versión original y quien desee obtener una adaptación aproximada ha de acudir a la reproducción de la conferencia de enero de 2000, la cual ha intercalado parte de esos mapas, fotos y canciones (que ahora, por supuesto, no suenan) ${ }^{25}$. En cualquier caso, el texto inicial de Darnton ha sido un proyecto nuevo, imposible de afrontar con los medios tradicionales y, lo que es más importante, un primer paso, una apuesta atrevida, distinta de todo cuanto se había hecho hasta el momento en el campo de la historia digital. En ese sentido, pues, nos ha mostrado que podemos empezar mezclando escritura tradicional e hipertexto y que eso no sólo no daña al dis-

22 Véase la columna de Quinlan, Sean: «With Darnton into Cyberspace: The $A H R$ 's New Avatar», Perspectives Online, vol. 38, núm. 3 (marzo de 2000):

http://www.historians.org/perspectives/issues/2000/0003/0003new2.cfm

23 Muchas de las páginas de internet que aluden a ese texto de Darnton remiten a esa antigua ubicación: http://www.indiana.edu/ ahr/darnton/. Sin embargo, el resultado es tan descorazonador como, por otra parte, habitual: «Error 403 - Restricted»

24 El resultado se puede ver en http://www.historycooperative.org/journals/ahr/105.1/ ah000001.html. Al parecer, la revista tiene previsto recuperar el texto y sus aditamentos. De ser así, las afirmaciones que siguen deberían ser igualmente actualizadas.

25 Véase la nota 21. 
curso histórico, sino que puede revitalizarlo en muchos sentidos. Eso sí, tal cosa implica una nueva alfabetización por nuestra parte. O como dijo Carl Smith: «The only way to see to it that there is serious history on the web is to put it there ourselves» 26 .

\section{¿QUÉ CONSECUENCIAS PODEMOS EXTRAER DE TODO ELLO?}

Abramos de nuevo la perspectiva para concluir. Todos sentimos una natural fascinación ante este panorama, pues cualquier demanda parece poder ser satisfecha rápidamente con sólo unas pulsaciones en el ratón, lo cual está muy lejos de la necesaria conciencia crítica y de la imprescindible discriminación frente a los datos obtenidos. Si el éxito inevitable de la red estuviera en esta deriva (de evidentes implicaciones docentes e investigadoras), entonces nuestra actitud desembocaría en el escepticismo más absoluto. Es decir, la disposición que el usuario ha de adoptar ha de ser la de la participación activa, pues su pasividad como mero receptor de lo que otros producen conduce a la indefensión. Es evidente, por ejemplo, que en la nueva era digital una de nuestras obligaciones ha de ser ayudar a interrogarse sobre la naturaleza de estos nuevos documentos, ayudar a analizarlos y a contextualizarlos correctamente. Ocurre lo mismo que con un texto escrito, pues en todos los casos hay que potenciar la autonomía del lector, que es un ejercicio de inteligencia crítica y de libertad. Lo que nos preocupa no es solamente acumular conocimientos, sino desarrollar una conciencia crítica de la realidad, es decir, que nos podamos preguntar sobre cómo, por qué y quién produce informaciones. Pensar que la red es un simple contenedor de materiales es un craso error que inutiliza buena parte del valor potencial que la comunicación electrónica posee.

Esa situación se agudiza en lo que respecta a la época contemporánea, pues es la única en que se han generado y se generan documentos digitales. Es decir, no se trata sólo de reproducir fuentes preexistentes, sino de crear otras nuevas con medios desconocidos en otros periodos. Por otra parte, a ello debemos añadir la gran cantidad y la variedad tipológica de las fuentes disponibles. En nuestra época, todo el mundo está presente en la red, todos aquellos que generan información relevante para el historiador o el curioso ofrecen su voz, su versión de los hechos: gobiernos, medios de comunicación, instituciones y organismos de toda suerte y condición, e incluso personas, individuos que de otra manera quizá jamás hubieran podido dejarse oír.

A este problema se añade aún otro con el que está relacionado, pero de mayor alcance: el espejismo de que la historia está ahí fuera, en la red, ofrecida por sus protagonistas, y que sólo necesitamos capturarla, sin ninguna elabora-

26 «Can Do You Serious History on the Web?», Perspectives Online, vol. 36, núm. 2 (febrero de 1998): http://www.historians.org/perspectives/issues/1998/9802/9802COM.CFM 
ción. De nuevo, esta situación se produce especialmente con la época contemporánea. Cuando enseñamos, por ejemplo, la historia antigua o la medieval puede que aparezca como algo ajeno, muerto, de modo que su recepción puede ser más bien pasiva: se acepta lo que se transmite y se asume con ello el trabajo del historiador, que ha periodizado ese pasado, lo ha jerarquizado, etcétera. En cambio, cuando hablamos del mundo contemporáneo la historia entra a menudo en disputa con la memoria, con otros relatos de diversos protagonistas y, en definitiva, con la percepción que tenemos de la realidad que nos envuelve. En este caso, por ejemplo, el lector o el estudiante también necesitan familiarizarse con las herramientas del historiador, pero le resulta mucho más difícil porque no está habituado a ellas. La memoria, por ejemplo, habla de continuidades, al igual que ocurre con internet, y la historia impone la discontinuidad, inducida por el trabajo propio del conocimiento histórico, una discontinuidad que subraya el carácter del pasado, su condición de desaparecido. De ahí que a la historia en singular se opongan las memorias o los relatos en plural. De ahí que la memoria transmitida de una generación a otra o la realidad virtual que nos presenta internet se conviertan en extraordinarias fuentes de resistencia al tratamiento historiográfico del pasado.

Toda esta superabundancia de información prefigura lo que será la sociedad de la comunicación que vemos nacer. Frente a ella no queda otra opción que un esfuerzo de alfabetización digital. Lo contrario, lo que resulta más tentador, es utilizar internet como un simple depósito. Esta actitud refleja el mito de un acceso fácil al conocimiento a partir la red, la confusión entre información y conocimiento. En realidad, todo conocimiento es construcción y precisamente esta telaraña global también puede convertirse en una extraordinaria herramienta de trabajo, de construcción. En primer lugar por el alcance de las informaciones disponibles, ya se trate de recursos documentales o de recursos humanos. Pero también porque internet es un instrumento de comunicación. Nos coloca a todos en situación de comunicarnos, de construir nuestro trabajo en cooperación. 